\title{
PERANAN STRATEGI GURU DALAM MENGEMBANGKAN KARAKTER ISLAMI ANAK DI SEKOLAH
}

\author{
Oleh: Prof. Dr. H. Syaiful Anwar, M. Pd.
}

\begin{abstract}
Abstrack
Moral degradation that is now going on in Indonesian, assumed was sourced from ethical and moral crisis in religion. Akhlak and moral crisis is an indication of poor mentality of the nation and the decline of the national dignity. It can be one of sign to the destruction of the nation. Responding to these conditions, lately, character education has become one of the hot issues in education. Program of "character building" has become a priority in the era Minister of National Education (Mendiknas), Prof. Dr. Muhammad Nuh, to build the nation's character. In step of the ideals above, Islam is a religion that aims to form his people have morality and noble moral character. Therefore, character education that emphasizes ethical-religious dimension becomes relevant for application. From this, conceptually articulate character education to know how the Islamic perspective in looking at the issue of ethics and moral character in helping his people is very important to put forward. Therefore in this paper, the authors will discuss the issue comprehensively.
\end{abstract}

\section{Keyword: Education, Character building, Islamic Religion}

\section{A. Prolog: Renungan Filosofis Kondisi Pendidikan di Indonesia}

Dalam dua dekade terakhir ini pasca krisis multidimensional tahun 1998, bangsa Indonesia masih mengalami keterpurukan dan keterbelakangan. Persoalan yang sering muncul, mengemuka, dan hangat menjadi diskursus dikalangan civitas akademika maupun masyarakat luas berkaitan dengan hancurnya“ Bangunan" moral disemua lini kehidupan bangsa. Hal ini tercermin, diantaranya dari semakin meningkatkan kekerasan (anarkisme) dalam menyelesaikan masalah, korupsi yang semakin massif, terjadinya perkelahian antar pelajar, dan pelanggaran etika dan susila yang semakin vulgar.

Degradasi moral yang kini menimpa bangsa Indonesia diasumsikan bersumber dari krisis etika dan moral dalam beragama. Sebagai bangsa muslim terbesar didunia dan terkenal religius, tentunya hal ini menjadi sebuah ironi. Disatu sisi, agama mengajarkan tentang kebaikan, tetapi prilaku umatnya telah banyak berlawanan dengan nilai-nilai agama dan nilai luhur budaya sebagai 
bangsa timur yang religius. Krisis moral dan akhlak ini merupakan indikasi buruknya mentalitas bangsa dan merosotnya harkat dan martabat kebangsaan, dan karenanya dapat menjadi salah satu tanda kehancuran bangsa.

Merespon kondisi tersebut, belakangan ini pendidikan karakter telah menjadi salah satu isu hangat dalam dunia pendidikan. Program " character building" ini menjadi prioritas pada era kepemimpinan Menteri Pendidikan Nasional (Mendiknas), Prof. Dr. Muhammad Nuh untuk membangun karakter bangsa. Bahkan, pada peringatan puncak acara Hari pendidikan Nasional 2 Mei pada Tahun 2010 dan pada tahun 2011 ini, tema yang diusung adalah “ Pendidikan Karakter sebagai Pilar Kebangkitan Bangsa” (Raih prestasi, junjung tinggi budi perkerti) dan dicanangkan sebagai gerakan nasional. ${ }^{1}$

Gerakan ini mengisyaratkan bahwa dalam konteks membangun kehidupan bermasyarakat, berbangsa dan bernegara yang berakhlak dan berbudi pekerti, maka pendidikan karakter merupakan sebuah pondasi kuatnya. Hal ini sebagai mana dikatakan Prof. Dr. Muhammad Nuh bahwa “ pendidikan karakter tidak hanya untuk membangun karakter pripadi berbasis kemuliaan semata, tetapi secara bersamaan juga bertujuan membangun karakter kemulian sebagai bangsa, yang bertumpu pada kecintaan dan kebanggaan terhadap bangsa dan Negara". ${ }^{2}$

Dari pengertian diatas, dapat disimpulkan bahwa bangsa yang berkarakter adalah bangsa yang berbudi pekerti.Bahkan jauh sebelum itu, dalam sejarah perjuangan bangsa Indonesia, "Bung Besar" (panggilan Soekarno) mengajarkan nation and character building kepada rakyatnya dengan rasa kebanggaan.Hal ini dapat dikatakan, merupakan upaya dari seorang pemimpin yang visioner untuk mempersiapkan pembangunan manusia Indonesia yang beraklak budipekerti mulia kedepannya.

Setujuan dengan cita-cita diatas, Islam adalah agama yang bertujuan membentuk umatnya memiliki moralitas dan akhlak budi pekerti yng mulia. Oleh karenanya, pendidikan karakter yang menekankan dimensi etis-religius menjadi relevan untuk diterapkan. Dari ini, mengartikulasikan pendidikan karakter secara konseptual

\footnotetext{
${ }^{1}$ Harian Koran kompas.Tanggal 21 Mei 2010. Hal.1

2 Ibid. Hal. 2
} 
untuk mengetahui bagaimana prespektif Islam dalam memandang persoalan etika dan moral dalam membantu karakter umatnya sangat penting untuk dikemukakan. Untuk itu dalam makalah ini, penulis akan mengupas masalah tersebut secara komprehensip, namun demikian seperti pepatah " tak ada gading yang tak retak" sehingga keritik dan masukan pembaca yang bersifat konstruktif sangat penulis harapakan demi perbaikan makalah ini dan berkembangnya khazanah ilmu pengetahuan yang lebih maju.

\section{B. Terminologi Pendidikan Karakter}

Istilah kata " Character" secara etimologi dapat dipahami dari sejumlah bahasa. " Character" (latin) berarti instrumen of narking, " Charessin” (Prancis) berarti to engrave (mengukir), "watek" (Jawa) berarti ciri wanci, "watak" (Indonesia) berarti sifat pembawaan yang mempengaruhi tingkahlaku, ; tabiat ;perangai. ${ }^{3}$ Dari pengertian ini, karakter adalah sifat kejiwaan, kepribadian, akhlak atau budi pekerti yang menjadi cirri khas seseorang atau sekelompok orang.

Sedangkan secara luasnya, karakter diartikan sebagai sifat manusia pada umumnya dimana manusia mempunyai banyak sifat yang tergantung dari factor kehidupannya sendiri. Karakter merupakan nilai-nilai prilaku manusia yang berhubungan dengan tuhan yang maha Esa, diri sendiri, sesama manusia, lingkungan, dan kebangsaan yang terwujud dalam pikiran, sikap, perasaan, perkataan, dan perbuatan berdasarkan norma-norma agama, hukum, tatakrama, budaya, dan adat istiadat.

Karakter menurut Alwisol diartikan sebagai gambaran tingkahlaku yang menonjolkan nilai benar-salah, baik-buruk, baik secara ekplisit maupun implisit. ${ }^{4}$ terkait dengan ini, WYNNE (1991) mengatakan kata karakter berasal dari bahasa yunani yang berarti " to mark" (menandai) dan memfokuskan pada bagaimana mengaplikasikan nilai kebaikan dalam bentuk tindakan atau tingkah

\footnotetext{
${ }^{3}$ A. Doni koesoema. Pendidikan karakter (strategi mendidik anak di zaman global). Jakarta: Grasido.2007.Hal. 163

${ }^{4}$ Alwisol. (2006). Psikologi kepribadian . Malang: UMM. Hal. 8
} 
laku. ${ }^{5}$ oleh sebab itu seseorang yang berprilaku tidak jujur, kejam atau rakus dikatakan sebagai orang yang berkarakter jelek, sementara orang yang berprilaku jujur, suka menolong dikatakan sebagai orang yang berkarakter mulia. Jadi istilah karakter erat kaitannya dengan personality ( kpribadian) seseorang, dimana seseorang bias disebut orang yang berkarakter (aperson of character) jika tingkahlakunya sesuai dengan kaidah moral yang berlaku.

Karakter (character) mengacu pada serangkayan sikap (attitudes) dan prilaku (behaviors). Karakter meliputi sikap seperti keinginan untuk melakukan hal yang terbaik, kapasitas intelektual seperti berpikir kritis dan alasan moral, prilaku seperti jujur dan bertanggungjawap, mempertahankan prinsip-prinsip moral dalam situasi penuh keadilan, kecakapan interpersonal dan emosional yang memungkinkan seseorang berinteraksi secara efektif dalam berbagai keadaan, dan komitmen untuk berkontribusi dengan komunitas dan masyarakatnya. Karakteristik adalah realisasi perkembangan positif sebagai individu ( intelektual, social, emosional, dan etika). Individu yang berkarakter baik adalah seseorang yang berusaha melakukan hal yang terbaik. ${ }^{6}$

Dari uraian diatas, pendidikan karakter adalah suatu usaha yang menyeluruh agar orang-orang memahami, peduli, dan berprilaku sesuai nilai-nilai etika dasar atau terbentuknya pekerti yang baik sesuai dengan nilai yang ditanamkan, jujur, tulus, rendah hati, terbuka, adil, peduli, toleransi, suka membantu, kerjasama, saling menghormati, saling memiliki rasa kebersamaan dan gotong royong, rasa kesetia kawanan, demokrasi, tatakrama, sopan santun dan bertanggungjawab.

\footnotetext{
${ }^{5}$ Wynne, E.A. (1991). Character and academics in the elementary school In J.S. Benigna (ed). Moral Character, and civic education in the elementary school. New York: Teachers College Press. ${ }^{6}$ Tadkiroatun Musfiroh.(2008). Tinjauan berbagai aspek character building: pengembangan karakter anak melalui pendidikan karakter. Yogyakarta: Tiara Wacana Yogyakarta. Hal. 25
} 
Ratna Megawangi sebagai pencetus pendidikan karakter di Indonesia telah menyusun karakter mulia yang selayaknya diakjarkan kepada anak, yang kemudian disebut sebagai 9 (Sembilan) pilar yaitu $:^{7}$

1. Cinta tuhan dan kebernaran (love Allah, trust, reference, loyalty)

2. Tanggungjawab, kedisiplinan, dan kemandirian (responsibility, excellence, self reliance, discipline, order lines)

3. Amanah (trust workt hiness, reliability, honesty)

4. Hormat dan santun (respect, courtesy, obedience)

5. Kasih saying, kepedulian, dan kerjasama (love, compassion, caring, empathy, generousity, moderation, cooperation)

6. Percaya diri, kreatif, dan pantang menyerah (confidence, assercitiveness, creativity, resourcefulness, courage, determination and enthusiasm)

7. Keadilan dan kepemimpinan (justice, fairness, mercy, leadership)

8. Baik dan rendah hati (kidness, friendliness, humility, modesty)

9. Toleransi dan cinta damai (tolerance, flexibility, peacefulness, unity) (Ratna Megawangi, 2008: 7).

Ary Ginanjar Agustian (2007), dengan tiori ESQ menyodorkan pemikiran bahwa setiap karakter positif sesungguhnya akan merujuk kepada sifat-sifat mulia Allah, yaitu al- Asma al- Husna. ${ }^{8}$ Sifat-sifat dan nama-nama mulia tuhan inilah sumber inspirasi tiap karakter positif yang dirumuskan oleh siapapun.Dari sekian banyak karakter yang bias diteladani dari nama-nama Allah itu, Ary merangkumnya dalam 7 karakter dasar, yaitu jujur, tanggungjawab, disiplin, visioner, adil, peduli, dan kerjasama.

\footnotetext{
${ }^{7}$ Ratna Megawangi.(2008). Membangun SDM melalui pendidikan holistic berbasis karakter. Diambil pada tanggal 25 Agustus 2008 dari http:keyanaku.google pages.com/pendidikan holistik berbasis karakter.pdf

${ }^{8}$ Ary Ginanjar Agustiyan.(2007).Rahasia sukses membangun kecerdasan emosi dan spiritual.Jakarta:Arga. Hal.13
} 
Dari sudut pandang agama, ada lima tonggak pendidikan sebagaimana yang diutarakan Muhammad Ali Quthb (1988) guna penanaman nilai-nilai positif. Ke lima tonggak pendidikan tersebut adalah sebagai berikut: ${ }^{9}$

1. Menanamkan aqidah dan agama,

2. Ketaatan,

3. Kejujuran,

4. Amanah (dapat dipercaya),

5. Sifat Qona'ah (menerima yang diberikan tuhan kepadanya) dan ridha/ bersabar.

Menurut Paul Suparno, dkk. (2002) beberapa nilai kehidupan yang perlu dikenalkan dan ditanamkan pada siswa antara lain: ${ }^{10}$

1. Religiusitas (mensyukuri hidup dan percaya pada tuhan, sikap toleran, mendalami ajaran agama),

2. Sosialitas (hidup bersama secara benar, baik, dan tertib; saling menghargai, membantu, memperhatikan dan menghormati satu sama lain),

3. Gender (tidak membedakan peran gender : penghargaan terhadap perempuan, kesempatan beraktivitas yang sama luasnya bagi laki-laki dan perempuan, menghargai kepemimpinan laki-laki maupun perempuan),

4. Keadilan (hak dan kewajiban yang benar dan seimbang bagi semua orang),

5. Demokrasi (menerima perbedaan, saling menghargai, menerima kekalahan),

6. Kejujuran (menyatakan kebenaran sebagai penghormatan kepada sesame),

7. Kemandirian (berani mengambil keputusan secara jernih, percayadiri, menerima keunikan diri),

8. Daya jual (tidak mudah menyerah),

\footnotetext{
${ }^{9}$ Muhamad Ali Quthb.(1988). Sang anak dalam naungan pendidikan islam.Bandung: CV.Diponegoro. Hal.79-84

${ }^{10}$ Paul Suparno,dkk.(2002). Pendidikan budi pekerti disekolah-suatu tinjauan umum. Yogyakarta: Kanisius.Hal.71-76
} 
9. Tanggung jawab (berani menghadapi konsekuensi, mengembangkan hidup bersama secara positif ), dan

10. Penghargaan terhadap lingkungan alam (menggunakan sumber daya alam secara wajar dan seimbang, mencintai kehidupan , mengenali lingkungan alam dan penerapannya).

Dalam penenman dan pembentukan nilai-nilai dasar tersebut, sehingga dapat berwujut tingkahlaku/ karakter yang relatif bersifat permanen dan menjadi penuntun, pengarah, dan pengorganisasi aktivitas individu, maka Kilpatrick dan lickona yang mana merupakan pencetus utama pendidikan karakter, percaya bahwa keberadaan moral absolute itu perlu diajarkan kepada generasi muda agar mereka paham betul mana yang baik dan benar. ${ }^{11}$ Menurut lickona (1992: 51-62) menyebutkan bahwa pendidikan karakter yang lebih baik harus terdiri dari tiga komponen karakter (components of good character). ${ }^{12}$ Dalam pelaksanaannya harus melibatkan bukan saja aspek pengetahuan tentang moral atau " Knowing the good” ( moral knowing), tetapi juga perasaan/keinginan untuk berbuat kebaikan atau " desiring the good" atau " loving the good" ( moral feeling) dan perbuatan bermoral atau " acting the good" (moral action).

Kemudian, menurut Berkowitz dan Bier (2005) menyatakan bahwa dalam pembentukan karakter maka antara cognition, valuing, and affection harus berada pada garis kontinum yang seimbang. ${ }^{13}$ sebab kebiasaan berbuat baik tidak selalu menjamin bahwa manusia yang telah terbiasa tersebut secara sadar (cognition) menghargai pentingnya nilai karakter (valuing). Mungkin saja perbuatannya tersebut dilandasi oleh rasa takut untuk berbuat salah, bukan karena tingginya penghargaan akan nilai itu. Misalnya saja ketika seseorang berbuat jujur hal itu dilakukannya karena ia takut dinilai oleh orang lain, bukan karena keinginannya,

\footnotetext{
${ }^{11}$ Kil Patrick,W.(1992). Why johni can 't tell right from wrong. New York : Simon dan Schuster, Inc. Hal.40

${ }^{12}$ Lickona, T. (1992). Educating for character, how our school can teach respect and responsibility. New York : Bantam books. Hal.51-62

${ }^{13}$ Berkowitz ,M.W. Bier, Melinda C. (2005). What works in character education : A research driven guide for educators. John e. and Frances g. pepper university of Missouri - ST Louis . diambil pada tanggal 25 Agustus 2008 dari www.rucharacter .org/file/practitioners 518.pdf
} 
yang tulus untuk menghargai nilai kejujuran itu sendiri. Oleh sebab itu dalam pendidikan karakter diperlukan juga aspek perasaaan (Domein affection atau emosi).Memekai istilah Lickona (1992) komponen ini dalam pendidikan karakter disebut "desiring the good" atau keinginan untuk berbuat kebaikan.

Dari uraian diatas, secara sederhana dapat dipahami bahwa dalam pelaksanaan pendidikan karakter menginginkan adanya keterpaduan otak dan hati peserta didik. Pendidikan tidak saja menginginkan peserta didik menjadi pandai dalam berfikir, namun juga memiliki hati yang baik.

\section{Pendidikan Karakter Dalam Kerangka Pendidikan Nasional Indonesia}

Pembentukan manusia yang mempunyai karakter sudah menjadi fungsi dan tujuan pendidikan nasional Indonesia. Dalam undang-undang no 20 tahun 2003 tentang system pendidikan nasional pada pasal 3 yang menyebutkan bahwa pendidikan nasional berfungsi mengembangkan kemampuan dan membentuk karakter serta peradaban bangsa yang bermartabat dalam rangka mencerdaskan kehidupan bangsa. Sedangkan, tujuan pendidikan nasional Indonesia adalah untuk mengembangkan kemampuan potensi peserta didik agar menjadi manusia yang beriman dan bertakwa kepada tuhan yang maha Esa, berakhlak mulia, sehat berilmu, cakap, kreatif, mandiri dan menjadi warganegara yang demokratis serta bertanggungjawab. ${ }^{14}$

Pendidikan berkarakter bertujuan untuk menanamkan nilai-nilai social, menciptakan pribadi peserta didik yang sopan, beretika, dan mampu menghargai orang lain. Dengan kata lain peserta didik memiliki keimanan dan ketakwaan kepada tuhan yang maha esa, berakhlak mulia, berkarakter mulia, kompetensi akademik yang utuh dan terpadu, sekaligus memiliki kepribadian yang baik sesuai dengan norma-norma budaya Indonesia.

Dalam hal ini, manusia yang terdidik seharusnya menjadi orang bijak, yaitu yang dapat menggunakan ilmunya untuk hal-hal yang baik (beramal shaleh), dan dapat

${ }^{14}$ Undang-undang Sikdiknas No. 20 tahun 2003. PT: Media Abadi, Yogyakarta, 2005. Hal.6-8 
hidup secara bijak dalam seluruh aspek kehidupan berkeluarga, bertetangga, bermasyarakat, dan bernegara.Karenanya, sebuah sitem pendidikan yang berhasil adalah yang dapat membentuk manusia-manusia yang berkarakter yang sangat diperlukan dalam mewujutkan sebuah Negara kebangsaan yang terhormat.

Bahkan, sejak 2500 tahun yang lalu Socrates pernah berkata bahwa tujuan yang paling mendasar dari pendidikan adalah untuk membuat seseorang menjadi “ good and smart”. Seperti menurut Socrates : "than the man wo's going to be affine and good guardian of the city for us will in nature be filosopic, spirited, swift, and strong ". ${ }^{15}$ Terkait dengan itu, kesadaran guru akan hakekat mengajar yang sebenarnya, yaitu disamping sebagai proses transfer of cnauledge juga sebagai transfer of falue harus ditekankan. ${ }^{16}$

Dengan demikian, pembelajaran nilai-nial karakter tidak hanya pada tataran kognitif tapi menyentuh pada internalisasi, dan pengamalan nyata dalam kehidupan peserta didik sehari-hari dimasyarakat. Menurut Mochtar Buchori (2007), pendidikan karakter seharusnya membawa peserta didik ke pengenalan nilai cara koknitif (pengetahuan), penghayatan/ internalisasi nilai secara efektif, dan akhirnya ke pengamalan/ mempersonalisasi nilai-nilai karakter secara nyata dalam prilaku sehari-hari.

Menurut Doni Koesoema, (11//02/2010) seperti dimuat dalam kompas, ada tiga pilar pendididkan pilar dalam karakter yang perlu dikembangkan diindonesia yaitu: (1) Desain pendidikan karakter berbasis kelas, (2) desain pendidikan karakter berbasis kultur sekolah dan (3) desain pendidikan karakter berbasis komunitas. ${ }^{17}$ sehubungan dengan itu, dalam pendidikan karakter disekolah, semua komponen (stakeholder) harus dilibatkan, termasuk komponen-komponen pendidikan itu sendiri, yaitu isi kurikulum, proses pembelajaran dan penilaian,

\footnotetext{
${ }^{15}$ Bloom A.(1991). The repoblice of plato. Second edition . New York, NY: Basic books. Diambil pada tanggal 24 Agustus 2008 dari http: // books. Google. Co.id /book?. Hal.376

${ }^{16}$ Darmiyati Zuchdi, dkk. (2008). Laporan penelitian hibah penelitian tim pascasarjana: pendidikan karakter melalui pengembangan keterampilan hidup (Live skills develovmen) dalam kurikulum persekolahan. Yogyakarta: program pascasarjana UNY. Hal.2

${ }^{17}$ Log.Cit. Koran Harian Kompas.Tgl 11 Februari 2010.Hal. 1
} 
pengelolaan sekolah, pelaksanaan aktivitas atau kegiatan ko- kulikuler, pemberdayaan sarana prasarana, pembiayaan, dan ethos kerja seluruh warga dan lingkungan sekolah.

Akhirnya, pada hakikatnya pendidikan karakter hanya dapat membangun karakter bangsa apabila dibangun pada seluruh lini secara kolektif dan simultan, bukan hanya dilembaga pendidikan formal tetapi terintegrasi dengan lini struktural dan kultural. Oleh karena itu, melalui program pendidikan karakter ini diharapkan peserta didik menemukan contoh teladan yang baik (Uswatun hasanah) atau living moral exemplary mulai lingkungan keluarga, sekolah, hingga yang lebih luas yaitu pada masyarakat lingkungan sosialnya.

\section{Pendidikan Karakter dalam Perspektif Islam}

Dari uraian diatas, pendidikan karakter merupakan upaya untuk membentuk kepribadian seseorang melalui pendidikan budi pekerti.Sebenarnya pendidikan karakter bukanlah sesuatu yang baru dalam dunia pendidikan. Pendidikan karakter merupakan bentuk lain dari pendidikan akhlak, budi pekerti maupun pendidikan moral yang sudah tertata sejak lama. Bahkan jauh sebelum itu, dalam sejarah misi diutusnya nabi Muhamad SAW adalah untuk membangun karakter masyarakat jahiliyah Mekkah pada masa pra islam. Era dimana kemajuan diberbagai aspek terlihat, namun perilaku manusianya tidak dibingkai oleh moralitas dan budi pekerti yang mulia.

Berangkat dari khittah ini, kehadiran islam dimuka bumi menjadi pedoman hidup manusia dan untuk memberikan solusi yang tegas terhadap berbagai persoalan kemanusiaan, terutama berkaittan dengan etika/moral (akhlaq). Akhlaq adalah puncak nilai keberagamaan seorang muslim sebagai implementasi ketaqwaanya kepada Allah SWT dan Rasul- Nya. Dari hal ini, tujuan pendidikan karakter yaitu manusia bertaqwa yaitu manusia yang beriman dan memiliki akhlaq dan budi pekerti yang luhur.Karakter dibangun berdasarkan pemahaman tentang hakikat dan struktur kepribadian manusia secara integral, sehingga manusia berkarakter 
taqwa adalah gambaran manusia ideal yaitu manusia yang memiliki kecerdasan spiritual (spiritual quotient).

Kecerdasan spiritual inilah yang seharusnya paling ditekankan dalam pendidikan. Hal ini dilakukan dengan penanaman nilai-nilai etis religius melalui keteladanan keluarga, sekolah dan masyarakat, penguatan pengamalan peribadatan, pembacaan dan penghayatan kitab suci Al- Qur'an, penciptaan lingkungan baik fisik maupun social yang kondusif. Apabila spiritualitas anak sudah tertata, maka akan lebih mudah untuk menata aspek-aspek kepribadian lainnya. Maksudnya, kalau kecerdasan spiritual anak berhasil ditingkatkan, secara otomatis akan meningkatkan kecerdasan-kecerdasan lainnya seperti kecerdasan emosional (emotional quotient), kecerdasan memecah masalah (adversity quotient) dan kecerdasan intelektual (intellectual quotient).

Keterpaduan, keserasian dan pencahayaan Godspot (ruh) terhadap kalbu, akal, nafsu dan jasad jelas akan memaksimalkan kecerdasan dan fungsi msing-masing. Dalam konteks tujuan pendidikan, hal ini akan mampu membentuk anak didik yang memiliki kekokohan akidah (quwwatul aqidah), kedalam ilmu (quwwqtul ilmi), ketulusan dalam pengabdian (quwwqtul ibadah) dan keluhuran pribadi (akhlakul karimah).

Dalam tinjauan eksistesisme, dasar pembentukan karakter itu adalah nilai baik dan nilai buruk, sehingga terciptanya muslim yang kaffah (insan kamil). Daripada itu, nilai baik disimbolkan dengan nilai dari sifat-sifat tuhan dan nilai buruk disimbolkan dengan nilai dari sifat-sifat setan. Karakter manusia merupakan "pertarungan" antara akal, nafsu dan nurani. Dalam pandangan islam, nilai dari sifat-sifat tuhan berpusat pada "hati nurani" (Fuad/dhamir), suara hati ilahiyah yang memotivasi seseorang untuk selalu berada pada kondisi hanif atau dalam pancaran sinar ilahiyah (QS al-Najmu: 11). ${ }^{18}$ Sedangkan, nilai dari sifat-sifat

\footnotetext{
${ }^{18}$ Ary Ginanjar Agustian. Rahasia Sukses Membangun ESQ: Emotional Spiritual Quotient The ESQ Way 165: 6 Rukun iman dan 5 rukun islam. Jakarta : Arga Wijaya Persada, 2006.Hal.5
} 
setan berpusat pada nafsu manusia, berupa nilai-nilai yang a-moral yang bersumber dari nilai-nilai destruktif thaghut (setan).

Karenanya, niali-nilai dari sifat-sifat Tuhan dan etis moral berfungsi sebagai sarana pemurnian, pensucian, dan pembangkitan nilai-nilai kemanusiaan yang sejati (hati nurani).Pertama, kekuatan spiritual itu berupa iman, islam, ihsan dan taqwa, yang berfungsi membimbing dan memberikan kekuatan kepada manusia untuk menggapai keagungan dan kemuliaan (ahsani taqwim); Kedua, kekuatan potensi manuasia, berupa aqlus salim (akal yang sehat), qalbun salim (hati yang sehat), qalbun munib (hati yang kembali, bersih, suci dari dosa) dan nafsu mutmainnah (jiwa yang tenang). Ketiga, sikap dan prilaku etis. ${ }^{19}$ sikap dan prilaku etis itu merupakan implementasi dari kekuatan spiritual dan kekuatan kepribadian manusia yang kemudian melahirkan konsep-konsep normative tentang nilai-nilai budaya etis. Sikap dan prilaku etis itu meliputi: istiqamah (integritas), ihlas , jihad dan amal saleh.

Akhirnya, hati yang dipenuhi dengan sifat-sifat ilahiyah akan melahirkan orang yang berkarakter, yaitu orang yang bertqwa, memiliki integritas (nafs almutmainnah) dan beramal saleh. Aktualisasi orang yang berkualitas ini dalam hidup dan bekerja akan melahirkan akhlak budi pekerti yang luhur karena memiliki personality (integritas, komitmen dan dedikasi), capacity (kecakapan) dan competency yang bagus pula (professional).

Sebaliknya, nilai-nilai destruktif thaghut (setan) justru berfungsi sebaliknya yaitu pembusukan, dan penggelapan nilai-nilai kemanusiaan.Pertama, kekuatan thaghut. Kekuatan thaghut itu berupa kufr (kekafiran), munafiq (kemunafikan), fasiq (kefasikan )dan syirik (kesyirikan) yang kesemuanya itu merupakan kekkuatan yang menjauhkan manusia dari dari makhluk etis kemanusiaanya yang hakiki (ahsani taqwim) menjadi makluk yang serba material (asfala safilin); Kedua, kekuatan kemanusiaan negative, yaitu pikiran jahiliya (pikiran sesat),

\footnotetext{
${ }^{19}$ Imam al-Ghazali (1985). Misykat Cahaya-cahaya (Misykat al- Anwar). Terjemahan Mohamad Bagir. Bandung: Mizan. Hal.40
} 
qalbun maridl (hati yang sakit, tidak merasa), qabun mayyit (hati yang mati, tidak punya nuraini) dan nafsu 1-lawwamah (jiwa yang tercela) yang kesemuanya itu akan menjadi manusia menghamba pada ilahi-ilahi selain Allah berupa harta, jabatan dan kekuatan selain Allah berupa harta, jabatan dan kekuasaan (thaghut). Ketiga, sikap dan prilaku tidak etis . sikap dan prilaku tidak etis ini merupakan implementasi dari keagkuatan thaghut dan kekuatan kemanusiaan negatif yang kemudia melahirkan konsep-konsep normative tentang nilai-nilai budaya tidak etis (budaya busuk). Sikap dan prilaku tidak etis itu meliputi; takabur (congkak), hub al -dunya (materialistik), dlama dlalim (aniaya) dan amal sayyiat (destruktif). ${ }^{20}$

Akhirnya, hati yang dipenuhi dengan sifat-sifat thaqhut akan melahirkan orang yang berkarakter buruk, yaitu orang yang puncak keburukannya meliputi syirk, nafs lawwamah dan 'amal al sayyiat (destruktif). Akuntansi orang yang beramal thaghut ini dalam hidup dan bekerja akan melahirkan prilaku tercela, yaitu orang yang memiliki personality tidak bagus (hipokrit, penghianat dan pengecut) dan orang yang tidak mampu mendayagunakan kompetensi yang dimiliki.

Dalam konteks, pendidikan islam sebagai sebuah system pendidikan, tidak dipungkiri memiliki kontribusi yang cukup mapan untuk menyokong pembentukan karakter bangsa dengan berbagai strategi dan metodenya. Bahkan dalam sejarahnya, kemajuan yang dicapai peradaban islam dizaman kekhalifahan tak lepas dari keberhasilan dunia pendidikan. Pada zaman itu, kota-kota islam telah menjelma menjadi pusat pendidikan dan peradaban yang sangat maju. Tiga intelektual muslim terpandang dizaman kekhalifahan. Mereka adalah Ibnu Sina, Ibnu Khaldun serta Al- Ghazali. Mereka menanamkan gagasan dan pemikiran tentang pendidikan yang baik dan ideal bagi dunia islam.

Menurut Ibnu Sina, pendidikan atau pembelajaran itu menyangkut seluruh aspek pada diri manusia, mulai dari fisik, mental maupun moral. "pendidikan tidak

\footnotetext{
${ }^{20}$ Ibid.Hal.45
} 
boleh mengabaikan perkembangan fisik dan apapun yang memiliki pengaruh terhadap perkembangan fisik seperti olagraga, makanan, minuman, tidur, dan kebersihan, "tutur Ibnu Sina.Dalam pandangan Ibnu Sina, pendidikan tak hanya memperhatiakan aspek moral, namun juga membentuk individu yang menyeluruh termasuk, jiwa, pikiran, dan karakter. Al- Ghazali memberikan perhatian yang sangat besar untuk menempatkan pemikiran islam dalam pendidikan. Menurutnya, seluruh metode pendidikan harus berpegang teguh pada syariat islam. Al-Ghazali menekankan pentingnya pembentukan karakter dengan memberikan pendidikan karakter yang baik maka orang tua sudah membantu anak-anaknya untuk hidup sesuai jalan yang lurus. ${ }^{21}$

Dalam konteks kekinian, pendidikan karakter mampu mengembangkan konsep multiple intelligence secara utuh.Memaknai secara holistik, fitrah setiap anak dilahirkan memiliki akal, nafsu (jasad), hati dan ruh. Konsep inilah yang sekarang dalam islam terdapat beberapa istilah yang sangat tepat digunakan sebagai pendekatan pembelajaran. Konsep- konsep itu antara lain: tilawah, ta'lim, tarbiyah, ta'dib, tazkiyah dan tadlrib. ${ }^{22}$ Tilawah menyangkut kemampuan membaca; ta'lim terkait dengan pengembangan kecerdasan emosional (intellectual quotient); tarbiyah terkait kepedulian dan kasih saying secara naluriyah yang didalamnya ada asah, asih dan asuh; ta'dib terkait dengan pengembangan kecerdasan emosional (emotional quotient); tazkiyah terkait dengan pengembangan kecerdasan spiritual ( spiritual quotient); dan tadldrib terkait dengan kecerdasan fisik atau keterampilan (physical quotient atau adversity quotient).

Dalam karakter ini sasarannya adalah terbentuknya anak didik yang memiliki pemikiran jauh kedepan, kreatif dan inovatif.Sedangkan output-nya adalah anak yang memiliki sikap ilmiah, ulul albbab dan mujtahid.Ulul albab adalah orang yang mampu mendayagunakan potensi piker (kecerdasan intelektual/IQ) dan

\footnotetext{
${ }^{21}$ Ibid. Hal.47

${ }^{22} \mathrm{Al}-$ Abrasyiy, Muhamad' Athiyah. At-Tarbiyah al- islamiyah wa Falasifatuha (Mishr: 'isa al-Babiy al-Halabiy, 1975). Hal.76
} 
potensi dzikirnya untuk memahami fenomena ciptaan tuhan dan dapat mendayagunakan untuk kepentingan kemanusiaan.Sedangkan mujtahid adalah orang mampu memecahkan persoalan dengan kemampuan intelektualnya.Hasilnya yaitu ijtihat (tindakannya) dapat berupa ilmu pengetahuan maupun teknologi.Outcome dari pendidikan akal (IQ) terbentuknya anak saleh (waladun shalih).

Pendayagunaan potensi potensi piker dan dzikir yang didasari rasa iman pada gilirannya akan melahirkan kecerdasan spiritual (spiritual quotient/SQ). dan kemampuan mengaktualisasikan kecerdasan spiritual inilah yang memberikan kekuatan kepada guru dan siswa untuk meraih prestasi yang tinggi.Metode tarbiyah digunakan untuk membangkitkan rasa kasih sayang, kepedulian dan empati dalam hubungan interpersonal antara guru dengan murid, sesame guru dan sesame siswa. Implementasi metode tarbiyah dalam pembelajaran mengharuskan seorang guru bukan hanya sebagai pengajar atau guru mata pelajaran , melainkan seorang bapak atau ibu yang memiliki kepedulian dan hubungan interpersonal yang baik dengan siswa-siswinya. Kepedulian guru untuk menemukan dan memecahkan persoalan yang dihadapi siswanya adalah bagian dari penerapan metode tarbiyah.

Metode ta'dib digunakan untuk membangkitkan kalbu (EQ) dalam diri anak didik.Ta'dib lebih berfungsi pada pendidikan nilai dan pengembangan iman dan taqwa.Dalam pendidikan kalbu ini, sasarannya adalah terbentuknya anak didik yang memiliki komitmen moral dan etika.Sedangkan out put-nya adalah anak didik yang memiliki karakter, integritas dan menjadi mujjaddid.Mujaddid adalah orang yang memiliki komitmen dan etis dan rasa terpanggil untuk memperbaiki kondisi masyarakatnya. Dalam hal mujaddid ini Abdul Jalil (2004) mengatakan : “ banyak orang pintar tapi tidak menjadi pembaharu (mujaddid). Seseorang pembaharu itu berat resikonya.Menjadi pembaharu itu karena panggilan hatinya, bukan karena kedudukan atau jabatan”. 
Metode tazkiyah digunakan untuk membersihkan jiwa (SQ).Tazkiyah lebih berfungsi untuk mensucikan jiwa dan mengembangkan spiritualitas.Dalam pendidikan jiwa sasarannya adalah terbentuknya jiwa yang suci, jernih (bening) dan damai (bahagia).Sedangkan ouput-nya adalah terbentuknya jiwa yang tenang (nafs al-mutmainnah), ulul arham dan tazkiyah. Ulul arham adalah orang yang memiliki kemampuan jiwa untuk mengasihi dan menyayangi sesame sebagai manifestasi perasaan yang mendalam akan kasih sayang tuhan terhadap semua hamba-Nya .tazkiyah adalah tindakan yang senantiyasa mensucikan jiwanya dari debu-debu maksiat dosa dan tindakan sia-sia (kedlaliman).

Metode tadlrib (latihan) digunakan untuk mengembangkan keterampilan fisik, psikomotorik dan kesehatan fisik.Sasaran (goal) dari tadlrib adalah terbentuknya fisik yang kuat, cekatan dan terampil. Output-nya adalah terbentuknya anak yang mampu bekerja keras, pejuang yang ulet, tangguh, dan seorang mujahid.Mujahid adalah orang yang mampu memobilisasi sumber dayanya untuk mencapai tujuan tertentu dengan kekuatan, kecepatan dan hasil maksimal.

Sebenarnya metode pembelajaran yang digunakan di sekolah lebih banyak dan lebih bervariasi. Semua pendekatan dan metode pendidikan dan pengajaran (pembelajaran) haruslah mengacu pada tujuan akhir pendidikan yaitu terbentuknya anak yang berkarakter taqwa dan berakhlak budi pekerti yang luhur.Metode pembelajaran dikatakan mengemban misi suci karena metode sama pentingnya dengan substansi dan tujuan pembelajaran itu sendiri. Dalam jargon pendidikan dikatakan : al-thariqatu ahammu min al-maddah, wa al-ustadzu ahammu min al-thariqah.

Untuk mewujudkan anak didik yang berkarakter, salah satu komponen utama dalam pendidikan adalah peran guru.Tugas pada pendidik dan sekolah untuk menjadikan manusia menjadi makhluk baik yang beradab dan berbudi pekerti yang luhur. Rasulullah bersabda: tinta alim ulama lebih tinggi nilainya dari pada darah para syuhada. "(H.R. Abu Daud dan Tarmizi).Hadis tersebut 
menggambarkan, ketinggian kedudukan seseorang yang memiliki ilmu pengetahuan, karena dapat melahirkan manusia-manusia yang berfikir dan beramal.Namun, tentu seorang pendidik yang tinggi kedudukanya adalah mereka yang mampu melaksanakan amar makruf nahi mungkar (memerintahkan kebaikan dan mencegah kemungkaran). Mereka menggunakan prinsip tauhid dalam penyebaran iman, ilmu, amal, dan ihsan.

Abdurrahman Al Nahlawi menyebutkan, tanggung jawab guru untuk mendidik individu agar beriman kepada Allah dan melaksanakanya syariatNya.Guru juga mendidik siswa agar beramal saleh, bahkan mendidik masyarakat untuk saling menasehati dalam melaksanakan kebenaran dan kesabaran.(Q.S. $A l$ Ashr). Konsekuensinya, siapa yang memuliakan guru secara tidak langsung telah memuliakan Rasulullah Saw. Tentu tak ada dikotomi antara guru sekolah umum dan sekolah agama. Sebaliknya, bila durhaka kepada guru, berarti durhaka kepada Rasulullah Saw dan Allah Swt pasti murka. Tentunya seorang guru harus memiliki kualitas yang baik dari segi akademik, akhlak, maupun amalan dalam keseharian. Ulama Al Kanani menyebutkan beberapa syarat sebagai guru.

Pertama, hendaknya sadar akan pengawasan Allah Swt dalam segala perkataan dan perbuatan. Guru memegang amanah Illahi yang amat berat, hingga ia tidak berani mengkhianati. Kedua, guru hendaknya memuliakan ilmu, sehingga tidak berhak mengajarkan kepada orang-orang yang hanya mengejar duniawi. Ketiga, guru bersikap zuhud dengan mencari dunia, sekedar memenuhi kebutuhan pokok diri dan keluarganya. Keempat, hendaknya guru tidak berorientasi kepada persoalan duniawi, dengan mendudukkan ilmu sebagai alat untuk mencari jabatan, harta, persoalan duniawi, dengan mendudukkan ilmu sebagai alat untuk mencari jabatan, harta, kebanggaan, atau gelar. Kelima, hendaknya guru menjauhi usahausaha yang hina dalam pandangan Islam dan menjauhi kondisi yang bisa menjatuhkan harga dirinya dimata orang banyak. Keenam, guru hendaknya memelihara syi'ar Islam, seperti memelihara shalat berjamaah di masjid, mengucapkan salam, dan menjalankan amar makruf nahi mungkar. Guru juga 
hendaknya rajin dalam melaksanakan sunnah agama, seperti dzikir, shalat tengah malam, dan membaca Al-Qur'an. Ketujuh, guru hendaknya mengisi waktu luang dengan hal-hal bermanfaat, seperti membaca dan mengarang. Guru juga hendaknya selalu belajar dan tidak merasa malu menerima ilmu dari orang lain. Dengan guru seperti itu, akan bisa mewarnai pendidikan menjadi pendidikan berkarakter.

\section{PENUTUP}

Berdasarkan uraian diatas, maka sudah selayaknya dalam pelaksanaan pendidikan berbasis karakter yang memiliki landasan yang berwawasan Islam, dalam hal ini dengan berpandu kepada Al-Qur'an dan Hadits sebagai sumbernya, sehingga akhir dari tujuan pendidikan dapat terwujud dan menciptakan insan berbudi pekerti, sebagaimana tujuan pendidikan Islam. 


\section{DAFTAR PUSTAKA}

Doni koesoema, Pendidikan karakter (strategi mendidik anak di zaman global), Jakarta: Grasido, 2007

Alwisol, Psikologi kepribadian . Malang: UMM. 2006

Wynne, E.A, Character and academics in the elementary school In J.S. Benigna (ed). Moral Character, and civic education in the elementary school. New York: Teachers College Press, 1991

Tadkiroatun Musfiroh, Tinjauan berbagai aspek character building: pengembangan karakter anak melalui pendidikan karakter. Yogyakarta: Tiara Wacana Yogyakarta, 2008

Ary Ginanjar Agustiyan, Rahasia sukses membangun kecerdasan emosi dan spiritual.Jakarta:Arga, 2007

Muhamad Ali Quthb, Sang anak dalam naungan pendidikan islam.Bandung: CV.Diponegoro, 1988

Paul Suparno,dkk, Pendidikan budi pekerti disekolah- suatu tinjauan umum. Yogyakarta: Kanisius, 2002

Kil Patrick,W, Why johni can 't tell right from wrong, New York : Simon dan Schuster, Inc, 1992

Lickona, T, Educating for character, how our school can teach respect and responsibility, New York : Bantam books, 1992

Berkowitz ,M.W. Bier, Melinda C, What works in character education : A research-driven guide for educators, John e. and Frances g. pepper university of Missouri - ST Louis, 2005

Bloom A, The repoblice of plato, Second edition . New York, NY: Basic books. Diambil pada tanggal 24 Agustus 2008 dari http: // books. Google. Co.id /book, 1991

Darmiyati Zuchdi, dkk, Laporan penelitian hibah penelitian tim pascasarjana: pendidikan karakter melalui pengembangan keterampilan hidup (Live skills develovmen) dalam kurikulum persekolahan. Yogyakarta: program pascasarjana UNY, 2008 
Ary Ginanjar Agustian, Rahasia Sukses Membangun ESQ: Emotional Spiritual Quotient The ESQ Way 165: 6 Rukun iman dan 5 rukun islam, Jakarta : Arga Wijaya Persada, 2006

Imam al-Ghazali, Misykat Cahaya-cahaya (Misykat al-Anwar), Terjemahan Mohamad Bagir. Bandung: Mizan, 1985

Al- Abrasyiy, Muhamad' Athiyah, At-Tarbiyah al- islamiyah wa Falasifatuha, Mishr: 'isa al-Babiy al-Halabiy, 1975 